\title{
Elderly Friendly City Concepts and Indicators
}

\section{Fatemeh Estebsari}

* PhD of Health Education \& Promotion, Assistant Professor, Department of Community Health nursing, School of Nursing \& Midwifery, Shahid Beheshti University of Medical Sciences, Tehran, Iran. (Correspoun Author) fa_estebsari@ yahoo.com.

Zahra RahimiKhalifeh Kandi PhD Student of Health Education \& Promotion, Department of Health Education, School of Public Health, Iran University of Medical Sciences, Iran

Kimya Estebsari

BSc, Medvifery and Maternal Health, Azna, Khat-Al- Anbia Network, Lorestan University of medical science, Lorestan, Iran.

Davoud Mostafaei

PhD of Health Services Management, Shahid Beheshti University of Medical Sciences, Tehran, Iran

Received: 02 July 2019

Accepted: 05 December 2019

Doi: 10.29252/ijhehp.8.1.5

\section{ABSTRACT}

Population aging and urbanization are two global trends that together form one of the challenges of the 21st century. The purpose of this study was to the concept of age friendly city and its indicators.

The findings of the study were classified into three areas of the history of the age friendly city, the definition of the age friendly city, the age friendly city indicators and Programs, and the content of each of the Indicators.

The findings of this study can be considered as the basis for designing elderly friendly cities in order to improve the quality of life of the elderly and promote active aging. In this regard, it is necessary to pay special attention to the appropriateness of the criteria with the cultural and social conditions in Iran Keywords: Elderly, Aging, Age Friendly City.

Paper Type: Editorial.

Citation (Vancouver): Estebsari F, RahimiKhalifeh Kandi Z, Estebsari K, Mostafaei D. Concepts of Age Friendly City. Iran J Health Educ Health Promot. 2020;8(1): 5-9.

- Citation (APA): Estebsari F., RahimiKhalifeh Kandi Z., Estebsari K., Mostafaei D. (Spring 2020). Concepts of Age Friendly City. Iranian Journal of Health Education \& Health Promotion., 8(1), 5-9. 


\section{مفاهيم و شاخصهاى شهر دوستدار سالمند}

\section{جكيده}

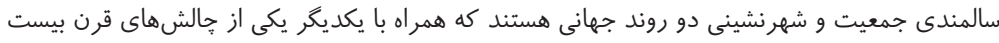

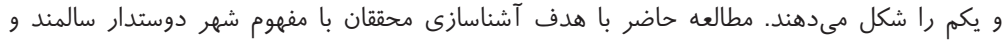
شاخصهاى انجام يذيرفت.

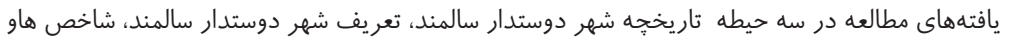

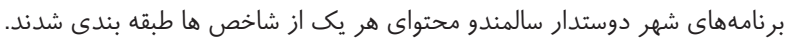

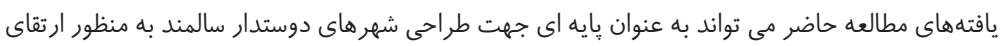

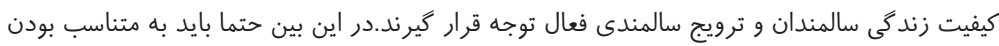

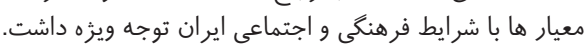

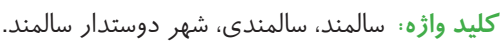

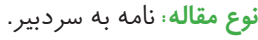

> استناد (ونكوور): استبصارى ف، رحيمى خليفه كندى ز، استبصارى ك، مصطفايى د. مفاهيم و شاخصهاى

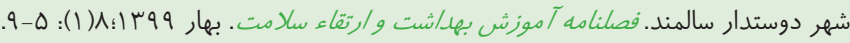

4 استناد (APA) : استبصارى، فاطمه؛ رحيمى خليفه كندى، زهر أ: استبصارى، كيميا؛ مصطفايى، داود. (بهار

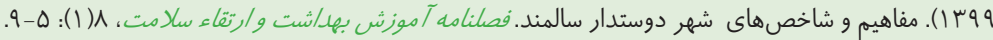

كارشناس، شبكه بهداشت خاتم النبياء ازنا، دانشكاه

$$
\text { علوم بواوشكى لرستان، لرستان، ايران. }
$$

دكتراى مديريت خدمات بهداشتى درمانى، دانشكاه علوم يزشكى شهيد بهشتى، تهران، ايران 
سازمان بهداشت جهانى در سال 9 . • ب، شبكهى جهانى شهرهاى

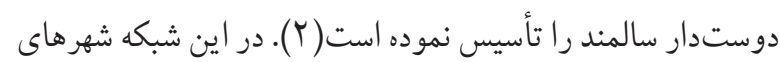
دوستدار سالمند به يكديخر و به سازمان بهداشت جهانى مرتبط

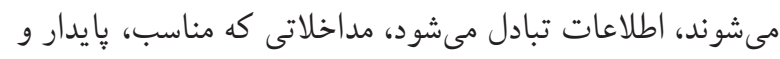
مقرون به صرفه براى ييشرفت زندگى سالمندان مىباشد، رواج

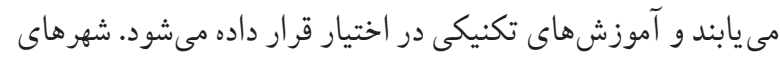

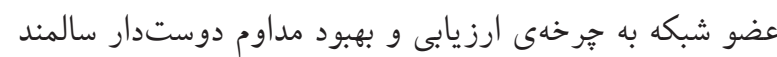

بودن تعهد دارند( (1).

شهر دوستدار سالمند شهرى است كه فرصت ها براى سلامت،

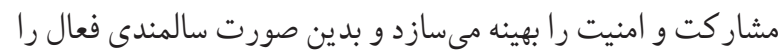

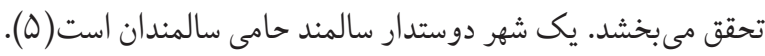
در يك شهر دوستدار سالمند سياستها، خدمات، تنظيمات و ساختار شهرى مرتبط با سالمندى فعال مثل شناسايى ظرفيتها و منابع

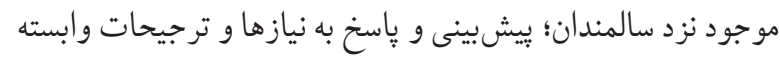
به سن افر اد؛ احترام به تصميمات و سبك زندكى سالمندان؛ محافظت از سالمندان در معرض آسيب؛ بهبود فعاليت و همكارى سالمندان

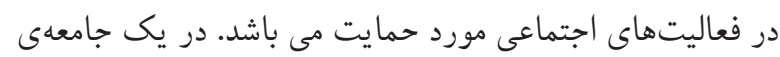

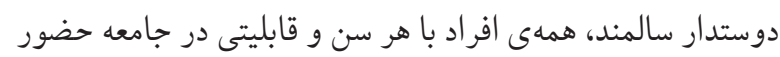

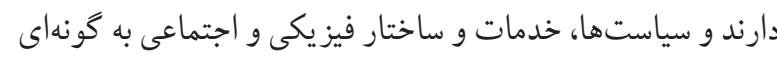
طر احى مى شود كه همه سالمندان حمايت شوند و قابليت سالمندى

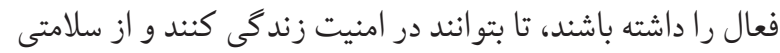

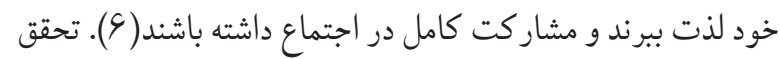
سالمندى فعال از روى فاكتورهاى شخصى، اجتماعى، اقتصادى و

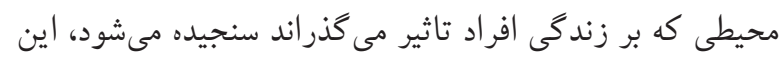

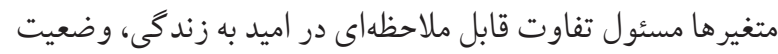

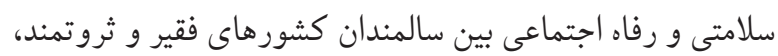

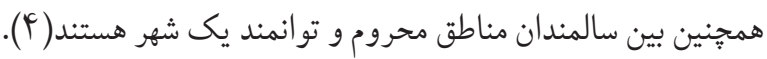

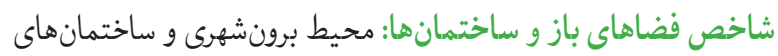
عمومى تأثير مهمى بر تحرك، استقلال و كيفيت زندكى افراد

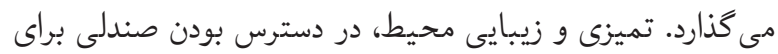

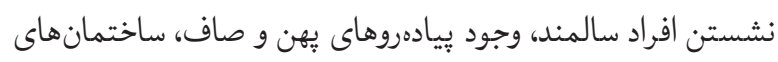

سالمندى فعال كه پايه و دليل اصلى شكل گيرى پروزنى شهر

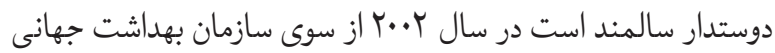
مطرح شد( (1). يروزهى شهر دوستدار سالمند براى نخستين بار

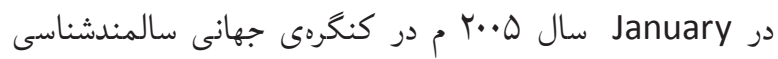
و سالمندان در Rio de Janeiro بارور شد و بلافاصله توانست

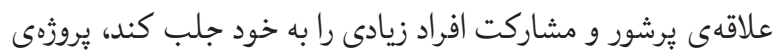

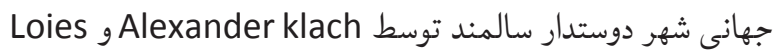
plaffe

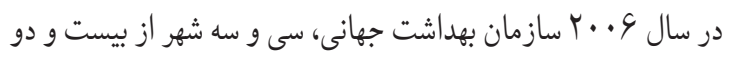
كشور را براى تصميم گيرى در مورد شاخصهاى كليدى فضاى شهرى

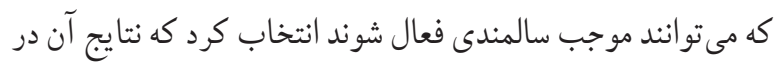

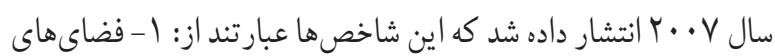

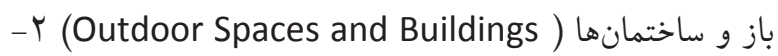
(Housing) ب- مشار كت اجتماعى) (Social Participation) ץ- حمل و نقل(Transportation) ه- - تكريم سالمندان و مشموليت اجتماعى(Respect and Social Participation) و- اشتغال و و

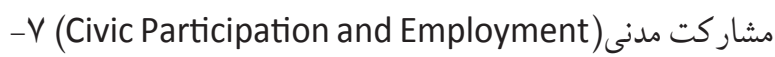
اطلاعات و ارتباطات (Communication and Information) 1- حمايت اجتماعى و خدمات سلامتى(Community Support (شكل l)( and Health Services

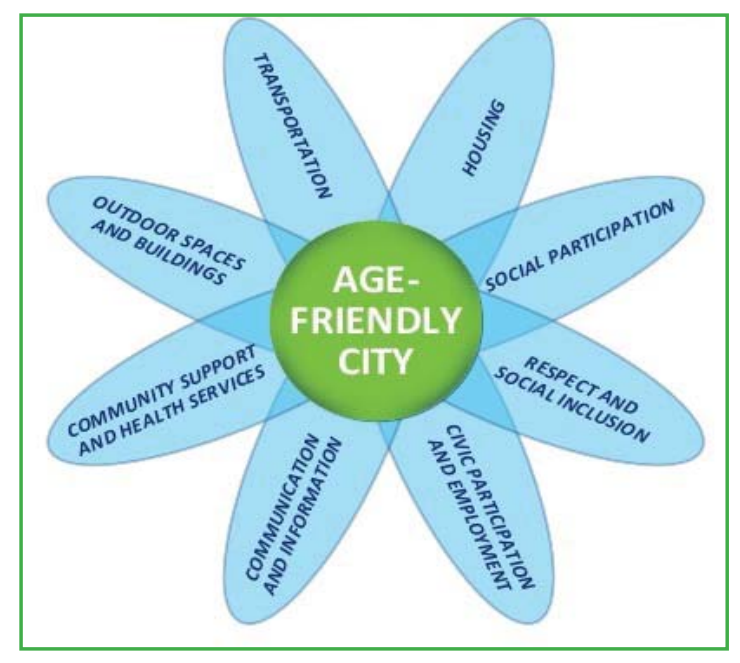

شكل ا. شاخصهاى شهر دوستدار سالمند، منبع سازمان بهداشت جهانى(r) 
شهر دوستدار سالمند فرصت براى اشتغال سالمندان وجود دارد. بازنشستكى يك انتخاب است نه اجبار. تبعيضات سنى در دسترسى برى

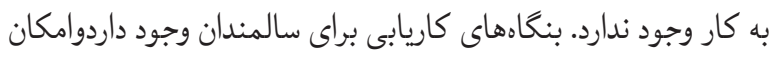

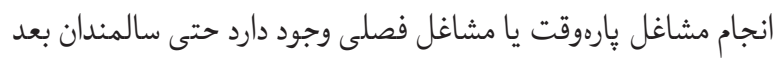
از بازنشستكى، براى كسب مهارتهاى جديد آموزش داده مي شوند.

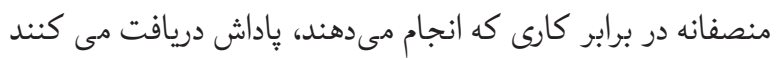
و از حقوق آنان حق بيمه كسر نمىشود(ب).

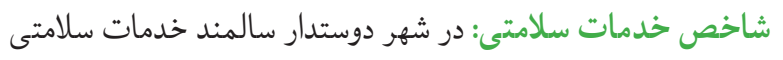
بايد در تمامى نقاط شهر در دسترس باشندو حمل و نقل به اين مكانها

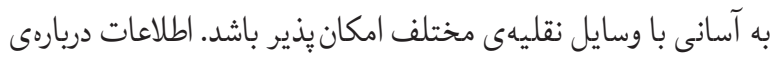
خدمات سلامتى و حمايتى روشن و دردسترس باشند. ارائهدهندههاى باى بائ

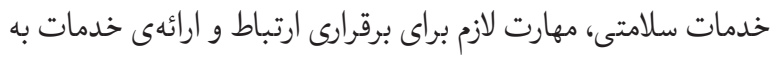
سالمندان را داشته و رفتارى محترمانه نسبت به سالمندان دارند(ץ).

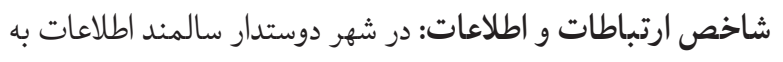

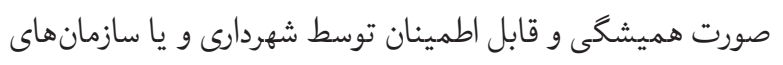
داوطلبانه در نزديكى محل سكونت سالمندان و يا نزديك محل هايى ونى كه معمولأ سالمندان با آنها سر و كار دارند، توزيع مى گردئ درد. اطلاعات

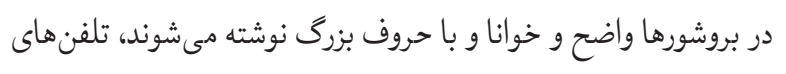
خدمتدهنده اطلاعات لازم را به صورت آرام و شمرده انتقال مى دهند. تجهيزات الكترونيك موجود در بانكها و يا مكانهاى ديكر دكمهاى

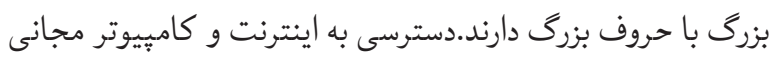

و يابا هزينهى اندك درمكانهاى عمومى وجود دارد(ץ).

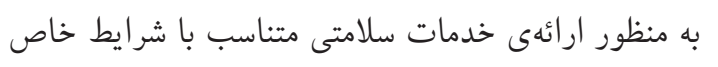

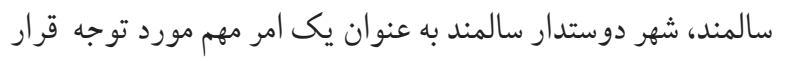

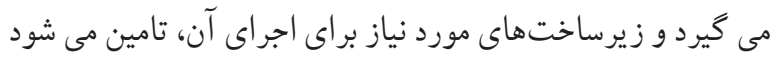

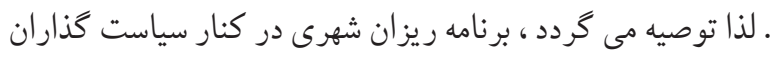

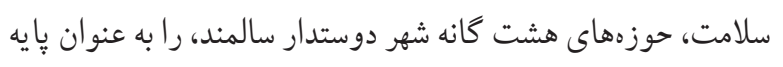
اى جهت ارتقاى محيطهاى حامى سلامت سالمندان مورد توجه قرار دهند، تا سبب تسهيل ارتقاى سالمندى فعال در جامعه گردد.
مناسب سالمندان كه مجهز به آسانسور، سراشيبى، درهاى بزرگ، راه كافى و خدمترسانى خوب به سالمندان از جمله مواردى ارتقاى شاخصهاى فضاى شهرى و ساختمانهاى شهر دوستدار سالمند است(ب). (r). (1)

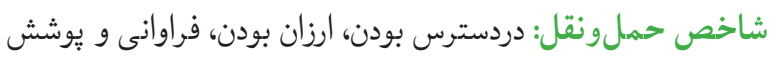
دهى خوب خدمات حملونقل در مناطق مختلف شهرى، سوار شدن

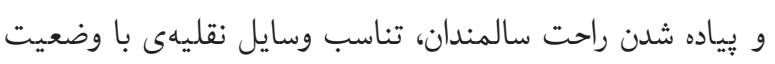
سالمندان، رعايت حق تقدم سالمندان بخصوص نشستن روى صندلى، رئه

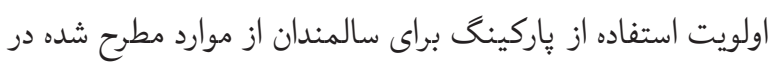
شاخص حملونقل مى باشند(r).

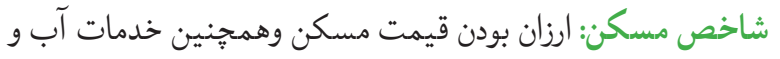
برق و كاز، طراحى مناسب خانه و تعديل فضاى خانه براى سالمندان

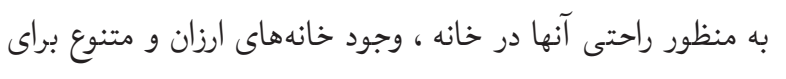
سالمندان ناتوان ضعيف، آكاهى سالمندان دربارهى وجود اين خانهها

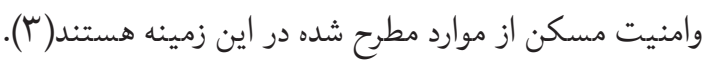

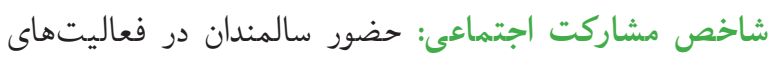
فرهنكى، اجتماعى، معنوى به همراه خانواده به سالمندان اين امكان

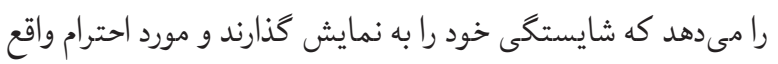
شوند. سالمندان خواستار فرصتهايى براى برقرارى روابط اجتماعى

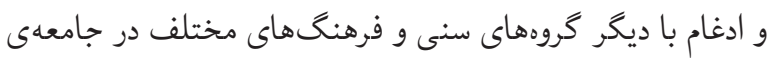

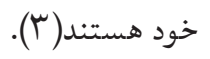
شاخص تكريبم سالمندان و مشموليت اجتماعى: سالمندان رفتارهاى هون مغايرى را تجربه مى كنند، از يك سو بسيارى از آنها احساس احترام

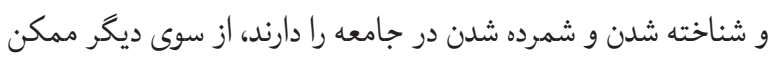
است تجربهى در نظر گرفته نشدن از سوى خانواده و جامعه را داشته باشند. در بروزّى شهر دوستدار سالمند، نياز اساسى براى تعامل بين نسل ها در رويدادهاى مختلف در كنار هم عنوان شده است كه به دروسي كمك زيادى به ايجاد حس احترام در آنها مى كند(ب). شاخص مشاركت مدنى و اشتغال: بسيارى از سالمندان اشتياق

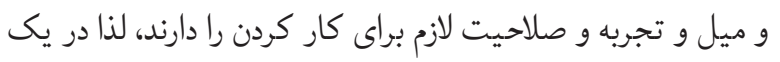




\section{References}

1. Lui CW, Everingham JA, Warburton J, Cuthill M, Bartlett $H$. What makes a community age-friendly: A review of international literature. Australasian journal on ageing. 2009;28(3):116-21. [DOI:10.1111/j.17416612.2009.00355.x] [PMID]

2. Organization WH. WHO Age-friendly cities project methodology: Vancouver protocol. Genebra; 2007.

3. Organization WH. Global age-friendly cities: A guide: World Health Organization; 2007.

4. Lai MM, Lein SY, Lau SH, Lai ML. Modeling Age-Friendly
Environment, Active Aging, and Social Connectedness in an Emerging Asian Economy. Journal of aging research. 2016;2016:2052380.

[DOI:10.1155/2016/2052380] [PMID] [PMCID]

5. Fitzgerald KG, Caro FG. An overview of age-friendly cities and communities around the world. Journal of Aging \& Social Policy. 2014;26(1-2):1-18. [DOI:10.1080/08959420 .2014.860786] [PMID]

6. Steels S. Key characteristics of age-friendly cities and communities: A review. Cities. 2015;47:45-52. [DOI:10.1016/j.cities.2015.02.004] 